\title{
CADÁVERES DE CÃES PREPARADOS QUIMICAMENTE E EMBALADOS À VÁCUO - EFEITO CRÔNICO NA BIOMECÂNICA DO JEJUNO
}

\section{Natália Teresina Brandão Costa ${ }^{1}$, Geovana Coelho Ferreira ${ }^{2}$, Isabela Del Ponti ${ }^{3}$, Fabrício Singaretti de Oliveira ${ }^{4}$}

1,2,3,4 Universidade Estadual Paulista (UNESP) “Júlio de Mesquita Filho” - Faculdade de Ciências Agrárias e Veterinárias - Câmpus de Jaboticabal

DOI: $10.47094 /$ ICONRES.2021/21

Introdução: Pela busca ao bem estar animal métodos alternativos ao uso de animais vivos no ensino da cirurgia veterinária vêm sendo empregados, como o uso de cadáveres preparados quimicamente. Objetivo: Determinar a força máxima (em Newtons - N) de ruptura do jejuno, o deslocamento para a ruptura (em mm), além de realizar a avaliação microbiológica durante todo o processo e desenvolver um modelo anatômico para prática de cirurgia veterinária intestinal. Metodologia: Foram utilizados 8 cadáveres de cães, na amostra controle foram coletados 3 fragmentos de jejuno submetidos a análise biomecânica imediata. Seguida de solução contendo $120 \mathrm{ml} / \mathrm{kg}$ de solução com sal de cura, contendo $200 \mathrm{~g} /$ litro de cloreto de sódio, $10 \mathrm{~g} /$ litro de nitrito de sódio e $10 \mathrm{~g} /$ litro de nitrato de sódio, seguido da injeção de álcool etílico puro com 5\% de glicerina em relação ao volume do álcool, na quantidade de $150 \mathrm{ml} / \mathrm{kg}$ de peso corporal via artéria carótida comum. Cada cadáver foi colocado em embalagem plástica a vácuo e mantido refrigerado entre 0 e $4^{\circ} \mathrm{C}$. As análises biomecânicas foram realizadas nos dias 30, 60, 90 e 120. As análises microbiológicas foram feitas da embalagem de 2 cadáveres, escolhidos ao acaso, no líquido que extravasava. Resultados: Não houve diferença significativa entre os momentos, o teste ANOVA mostrou não haver diferença estatística significativa $(p=0,1339)$ entre a média das amostras controle e tratadas. A população microbiana não excedeu $8,4 \times 10^{2} \mathrm{UFC} / \mathrm{mL}$ nos

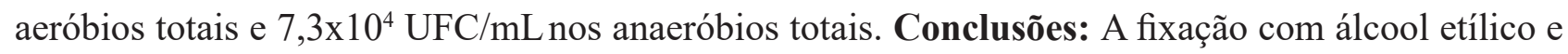
sais de cura, associado às embalagens a vácuo, é uma forma de baixo impacto ambiental e efetiva de conservar as características biomecânicas do jejuno fresco por pelo menos 120 dias, aliado à baixa contaminação microbiana, o que é recomendado para o ensino da cirurgia veterinária por mimetizar nos cadáveres fixados a resistência intestinal apresentada pelos cadáveres frescos.

Palavras-chave:Anatomia.Animal.Ensino.

Área Temática: Medicina Veterinária 